\title{
COVID-19 as a Factor Influencing Air Quality? A City Study in China
}

Aerosol and Air Quality Research

\section{OPEN ACCESS}

Received: April 10, 2021

Revised: April 10, 2021

Accepted: May 5, 2021

${ }^{*}$ Corresponding Author:

daizx@Ireis.ac.cn

\section{Publisher:}

Taiwan Association for Aerosol Research

ISSN: $1680-8584$ print

ISSN: 2071-1409 online

Copyright: The Author(s). This is an open access article distributed under the terms of the Creative Commons Attribution License (CC BY 4.0), which permits unrestricted use, distribution, and reproduction in any medium, provided the original author and source are cited.

\author{
Chengming $\mathrm{Li}^{1,3}$, Hui Shang ${ }^{2}$, Zhihao $\mathrm{Cui}^{3}$, Zhaoxin Dai ${ }^{1 *}$, Zhaoting $\mathrm{Ma}^{1}$ \\ ${ }^{1}$ Chinese Academy of Surveying and Mapping, Beijing, China \\ 2 Dongying Natural Resources Bureau, Dongying, Shandong, China \\ ${ }^{3}$ Shandong University of Science and Technology, Qingdao, Shandong, China
}

\section{ABSTRACT}

To prevent the spread of coronavirus disease 2019 (COVID-19), which emerged in late December 2019, the Chinese government immediately adopted lockdown measures, such as restricting traffic and closing factories. By analyzing the spatiotemporal distribution of the air quality index (AQI) values in Dongying, a city dominated by the petrochemical industry (specifically, petroleum exploration), during February 2020, when the strictest measures were in force, this study investigates the effect of short-term lockdowns on air quality. We observed a statistically significant reduction in the monthly average $\mathrm{AQI}-24.6 \%$, or an absolute decrease of 25.4 -compared to February 2019. Additionally, the difference between the maximum and the minimum hourly average AQI dropped to almost one-third of the value that in the normal time during winter.

We also assessed the influence of meteorological factors and industrial exhaust emissions. Quantitative analysis revealed a strong positive correlation $(p<0.01)$ between the AQI and exhaust emissions, confirming the latter's contribution to air pollution. However, this contribution shrunk by approximately 38.3\% during February 2020. Our results indicate that the improvement in air quality was related to traffic reduction and enterprise closures during the lockdown, which only marginally affected the spatial distribution of the AQI values. This research serves as a reference for controlling air pollution in Dongying and areas with similar conditions.

Keywords: COVID-19 pandemic, Air quality index (AQI), Spatiotemporal characteristics, Industrial exhaust emissions, Variations in air quality

\section{INTRODUCTION}

Due to rapid urbanization and industrialization, interest in environmental monitoring in China has greatly increased (Zhou et al., 2016). The Chinese government released a new National Ambient Air Quality Standard in 2012 (Zhao et al., 2018) and established a comprehensive network of air quality monitoring sites at the prefecture level in 2015. Air pollution can cause respiratory, cardiovascular, and cerebrovascular diseases through gas exchange in the lungs (Mannucci and Franchini, 2017; Glencross et al., 2020). Additionally, it can significantly reduce visibility and cause smog, which is inconvenient for residents' travel. The air quality index (AQI) is a dimensionless index describing air quality; it can be obtained by combining the levels of six major pollutants, namely fine particulate matter $\left(\mathrm{PM}_{2.5}\right)$, coarse particulate matter $\left(\mathrm{PM}_{10}\right)$, sulfur dioxide $\left(\mathrm{SO}_{2}\right)$, ozone $\left(\mathrm{O}_{3}\right)$, nitrogen dioxide $\left(\mathrm{NO}_{2}\right)$, and carbon monoxide (CO). Accurately identifying the spatiotemporal distribution of AQI characteristics is essential for targeted control of air pollution (Masiol et al., 2018).

A large number of studies have been conducted on the spatiotemporal characteristics of air quality worldwide, including studies based on remote sensing inversion of the aerosol optical depth (AOD), studies based on ground monitoring stations and studies based on modeling which is complementary to satellite and ground-based observations (Alsahli et al., 2018; Li et al., 2018). Studies based on remote sensing inversion usually focus on large-scale areas to provide a regional 
overview (Chudnovsky et al., 2014). Due to the high-frequency monitoring, research based on ground-monitored data is significant to explore the detailed patterns especially on the city scale (Huang et al., 2016; Wang and Tian, 2018). However, these studies have generally been based on non-special/normal situations. Toward the end of 2019, a coronavirus strain called coronavirus disease 2019 (COVID-19) emerged in Wuhan, China, and proved to be transmissible from human to human (Guo et al., 2020). To control the pandemic in China, the government implemented nationwide restrictions on traffic and industry on January 23,2020 , which greatly reduced human activity and emissions (Xu et al., 2020). Moreover, residential heating usually remained stable, but the industrial emissions may decrease abruptly. Researchers have pondered whether these restrictions affected air quality and, if so, what was the extent of the effect. Related research on relationships between air quality and the COVID-19 pandemic was quickly published (Dutheil et al., 2020). For example, Bauwens et al. (2020) reported that large reductions in $\mathrm{NO}_{2}(20-40 \%)$ occurred in cities in China, South Korea, western Europe, and the United States due to significantly reduced traffic emissions during the outbreak. Xu et al. (2020) investigated the influence of the COVID-19 pandemic on air quality in three cities in Hubei Province, China, and determined that strict COVID-19 control policies significantly improved air quality. The average concentrations of $\mathrm{PM}_{2.5}, \mathrm{PM}_{10}, \mathrm{SO}_{2}, \mathrm{CO}$, and $\mathrm{NO}_{2}$ in February 2020 were 30.1\%, 40.5\%, 33.4\%, 27.9\%, and 61.4\% lower than the levels in February 2017-2019, respectively. Chen et al. (2020a) demonstrated that quarantine measures led to a reduction in concentrations of $\mathrm{PM}_{2.5}, \mathrm{SO}_{2}, \mathrm{NO}_{x}$, and $\mathrm{CO}$ in Shanghai, but the reduction in $\mathrm{NO}_{x}$ led to increased levels of $\mathrm{O}_{3}$. Chauhan and Singh (2020) reported that in the U.S., a linear decline in $\mathrm{PM}_{2.5}$ was observed in the month of March, in New York City, pronounced linear reduction (32\%) is seen in $\mathrm{PM}_{2.5}$ during March 2020 compared with March 2019. Several studies have also assessed the effects of meteorological factors and air pollution on COVID-19 transmission in countries or cities such as Singapore (Pani and Lin, 2020), China (Liu et al., 2020), the United States (Gupta et al., 2020), Spain (Briz-Redón et al., 2021) and other countries (Pani and Lin, 2020). Their findings suggested that temperature variation, humidity, and air pollution may also be prominent factors affecting COVID-19 mortality. For instance, Ma et al. (2020) indicated that the diurnal temperature ranges and $\mathrm{SO}_{2}$ levels exhibited significant positive correlations with the COVID-19 pandemic in Wuhan, China, but relative humidity, $\mathrm{PM}_{2.5}$, and $\mathrm{PM}_{10}$ had significant negative correlations with the pandemic.

Most studies have used data from national control monitoring stations for their analyses, which may have low spatial and temporal resolutions. In addition, how the air quality of Dongying, a city known for petroleum exploration, was affected by factory closure during the lockdown is unknown. Identifiable changes could significantly affect future air quality management. These concerns motivated this research. In this study, a preliminary analysis examining the possible effects of COVID-19-related restrictions on air quality in the Dongying region, the first of its kind, was conducted. The objectives of the study were to (1) analyze spatiotemporal changes in the AQI distribution in Dongying from September 2019 to August 2020, (2) explore the effect of the short-term period on the AQI, (3) preliminarily discuss the magnitude of the effect on possible

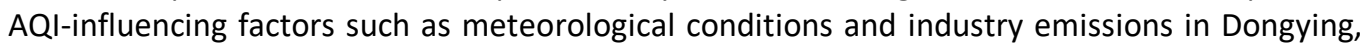
and (4) present policy recommendations for pollution prevention. The results would improve understanding of the spatiotemporal changes in air quality in Dongying, and the findings can provide scientific support for in-depth air pollution research. Moreover, the findings are meaningful for effective pollution prevention and management in Dongying.

\section{DATA AND METHODOLOGY}

\subsection{Study Area}

Dongying $\left(36^{\circ} 55^{\prime}-38^{\circ} 10^{\prime} \mathrm{N}, 118^{\circ} 07^{\prime}-119^{\circ} 10^{\prime} \mathrm{E}\right)$ is located in the northern part of Shandong Peninsula (Fig. 1). The terrain inclines from the southwest to the northeast in the direction of the Yellow River. It is characterized by a shorter, less windy, humid spring; a hotter summer with frequent precipitation; and a colder, drier winter. The city is critical for oil exploitation in China, and the petrochemical industry is the backbone of Dongying's thriving economy. In March 2019, air quality in Dongying ranked in the bottom 12 of 168 key cities. However, little research involving air pollution analysis has been conducted in Dongying, especially during the COVID-19 pandemic. 


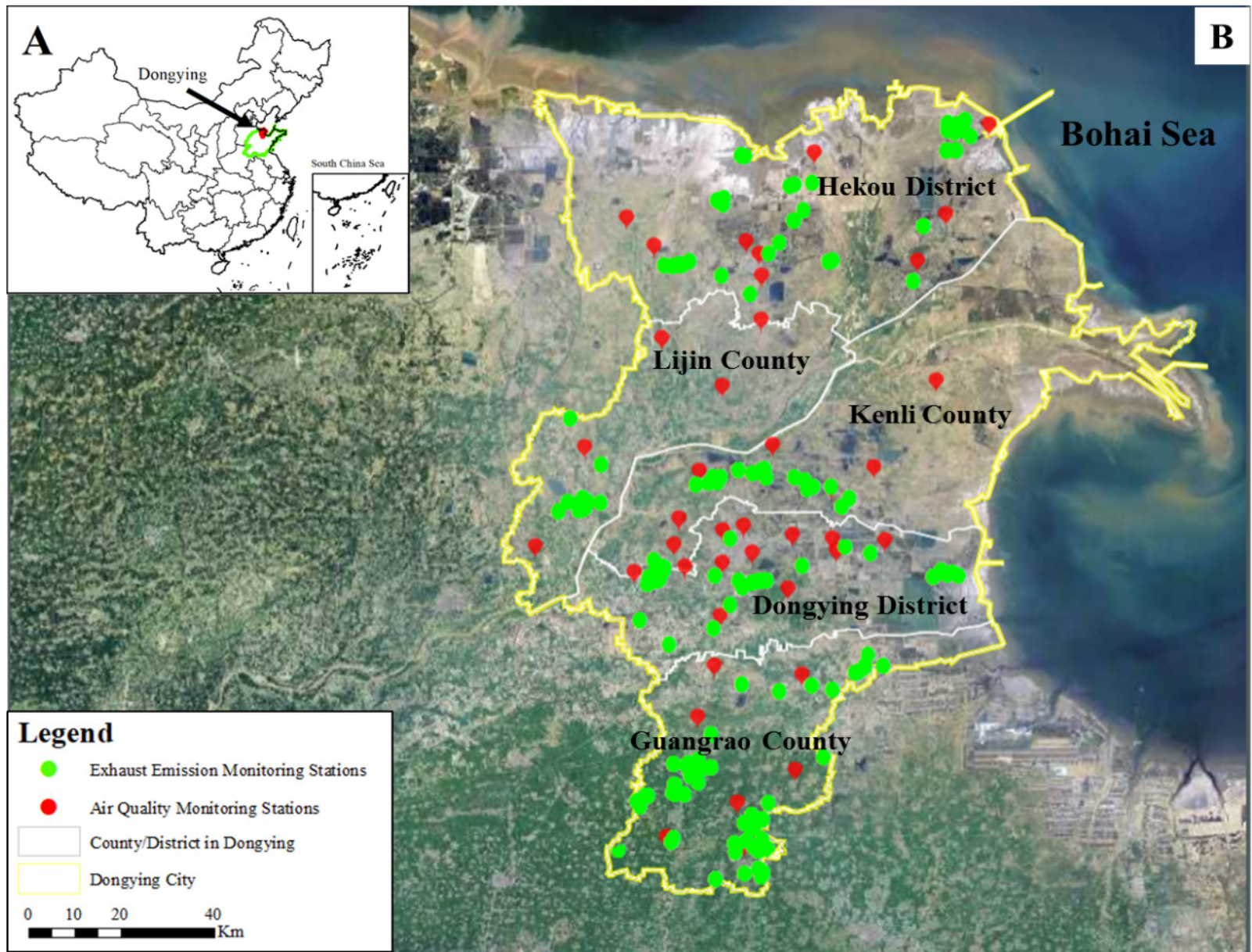

Fig. 1. Study area and the spatial distribution of monitoring stations: (A) Dongying and (B) monitoring sites.

An investigation of the spatiotemporal characteristics of air quality in this period is essential to understanding the effects of COVID-19 on air quality.

\subsection{Data Sources}

Ground monitoring data recorded by 42 national and municipal stations in Dongying from September 2019 to August 2020 were used this study. During this study period, February 2020 is regarded as the strictest lockdown period in Dongying of China based on the government report at http://www.gov.cn/xinwen/2020-02/22/content_5482131.htm and http://sd.people.com.cn/n2/ /2020/0324/c386910-33899319.html. In March, industries were permitted to resume production if they met appropriate requirements, and residents were allowed to travel. All the data were obtained by web crawling through the monitoring application programming interface provided by the Municipal Environmental Protection Bureau of Dongying (http://dydata.sd.gov.cn/). All acquired data are in units of hours, and the data comprised the following air pollutants: $\mathrm{PM}_{10}$, $\mathrm{PM}_{2.5}, \mathrm{O}_{3}, \mathrm{NO}_{2}, \mathrm{SO}_{2}$, and $\mathrm{CO}$.

The $A Q I$ is a dimensionless index that quantitatively describes air quality. In accordance with the National Ambient Air Quality Standard (GB 3095-2012) released by the Ministry of Environmental Protection in 2012, the AQI used in this study can be derived from the abovementioned six indicators, as indicated in Eq. (1) (Li et al., 2019). The data were acquired by automatic fixed air quality monitors through $24-\mathrm{h}$ continuous monitoring. Thermo Fisher $1405 \mathrm{~F}$ monitoring instruments were used to measure the air pollution concentrations. The AQI represents the maximum individual air quality indices of the pollutants. It can be divided into the following six levels: 0-50, 51-100, 101-150, 151-200, 201-300, and > 300. The corresponding air quality levels are excellent, good, lightly polluted, moderately polluted, heavily polluted, and severely polluted. As AQI values increase, air quality decreases: 
$I A Q I_{p}=\frac{\mid A Q I_{H i}-I A Q I_{L O}}{C_{H i}-C_{L O}}\left(C_{p}-C_{L O}\right)+I A Q I_{L O}$
$A Q I=\max \left(I A Q I_{1}, I A Q I_{2}, I A Q I_{3}, \cdots, I A Q I_{n}\right)$

where $I A Q I_{p}$ denotes the air quality subindex for air pollution $p ; C_{p}$ refers to the concentration of pollutant $p ; C_{L O}$ is a concentration breakpoint $\leq C_{p} ; C_{H i}$ denotes a concentration breakpoint $\geq C_{p}$; $I A Q I_{H i}$ denotes the index breakpoint corresponding to $C_{H i}$; and IAQILO is the index breakpoint corresponding to $C_{L O}$.

\subsection{Methodology}

With the hourly data, Node.js v12.18.3 (LTS) software (such as fs software modules) was applied to retrieve daily, monthly, and seasonal averages of the AQI in Dongying from 2019 to 2020. It should be noted that a valid check on hourly data was conducted to get rid of the problematic and missing data points before data processing tasks. According to GB 3095-2012, daily average is the arithmetic mean of natural daily 24-h average concentrations; monthly average is the arithmetic average of mean concentrations of each day in a month; and seasonal average is the arithmetic average of the mean concentrations of each day in a quarter. It should be noted that the Kriging method is applied in this paper due to the advantage of being smooth and intuitive in spatial interpolation. The Kriging method is a linear unbiased optimal estimation method which can give the optimal linear unbiased estimation (Wu et al., 2018; Mahajan et al., 2019).

To evaluate the effect of AQI factors in different periods, standardized coefficients (beta weights) were calculated. Standard coefficient here refers to the regression coefficient after equalizing the variance of dependent variable and independent variables; its absolute value directly reflects the degree of influence of an independent variable on a dependent variable. A standardized regression coefficient is computed by dividing a parameter estimate by the ratio of the sample standard deviation of the dependent variable to the sample standard deviation of the regressor. The equation is as follows:

$\beta_{i}=\alpha_{i} \times \frac{S D_{x i}}{S D_{y i}}$

where $\beta_{i}$ is the standardized coefficient of each influencing factor, $\alpha_{i}$ indicates the correlation coefficient of each influencing factor, $S D_{x i}$ means the standard deviation of $x_{i}$, and $S D_{x i}$ refers to the standard deviation of $y_{i}$.

To test the significance of the difference between the means of two or more samples, such as whether AQIs in the pandemic period were statistically different, an analysis of variance (ANOVA) was conducted (Chambers et al., 1992). ANOVA comprised one-way ANOVA and multifactor ANOVA.

\section{RESULTS AND ANALYSES}

\subsection{Temporal Changes of AQI}

\subsubsection{Monthly and Daily Characteristics}

Fig. 2 presents the changes in monthly AQI averages in Dongying from 2017 to 2020. The data can be downloaded from the Qingyue Open Environmental Data Center (https://data.epmap.org). Across the study period, the overall AQI of Dongying did not reach the excellent air quality standard of AQI $<50$. AQls were generally the highest in December and January, with a value of 129 , and in December, with a value of 96. This finding is consistent with the findings from 2016 to 2019 and previous results (Li et al., 2019). As indicated by Zhan et al. (2018), the high AQI in winter may be due to two reasons. One is that climate conditions, including frequent temperature inversion, low temperature, and low precipitation, are not conducive to air diffusion. The other reason is that coal heating increases sharply in winter, and the pollutants released by the burning of this fossil fuel exacerbate air pollution. By contrast, in autumn (September, October, and November), the weather in Dongying is warmer with stronger convection, resulting in better conditions for air diffusion. 


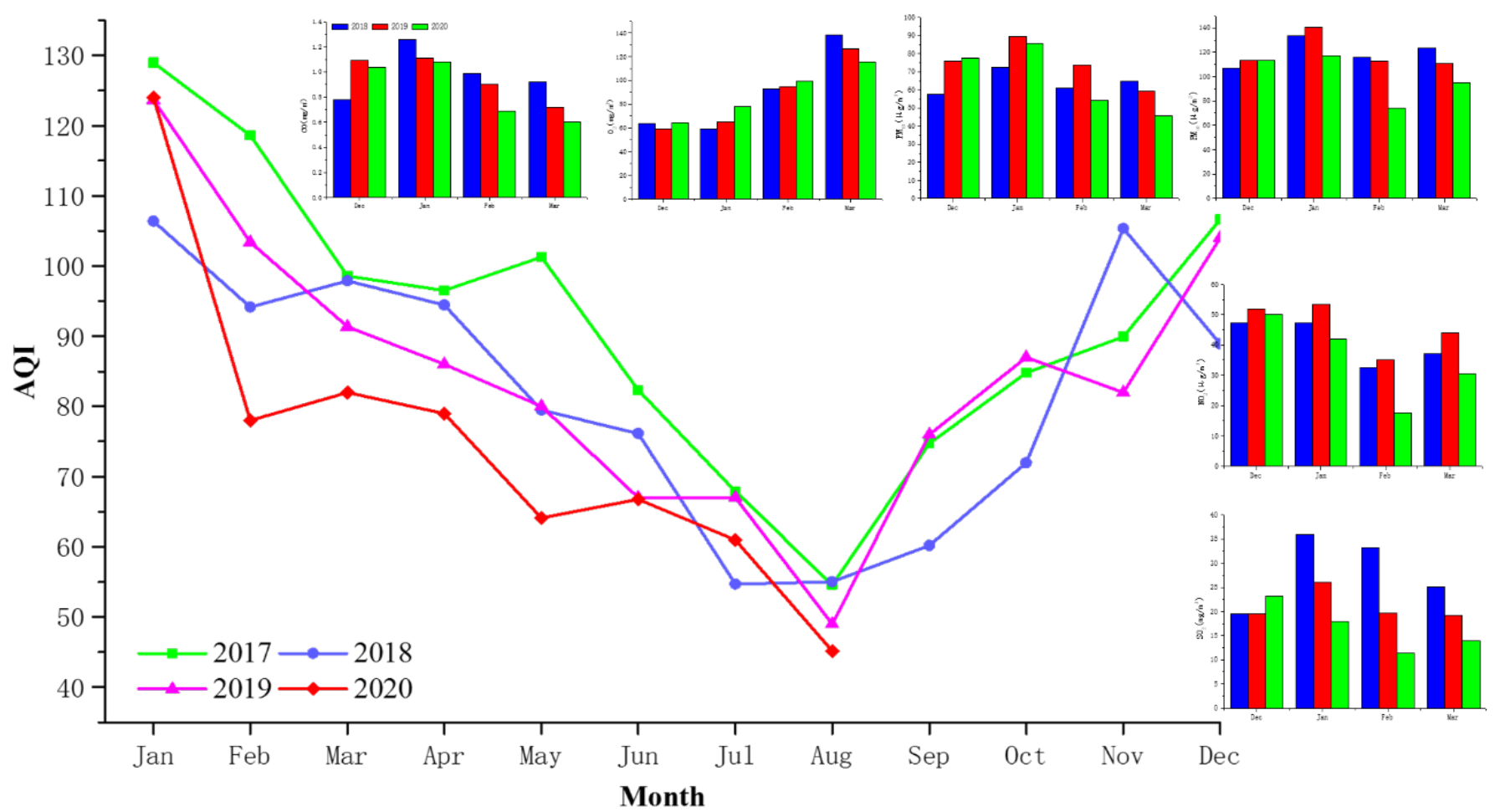

Fig. 2. Monthly AQI averages and six pollutants' averages during 2018 (blue bar), 2019 (red bar) and 2020 (green bar) for February in Dongying.

As illustrated as Fig. 2, it should be noted that in February 2020, which is also a part of the winter season, the AQI reduced rapidly. In order to investigate the COVID-19 effects on AQI, the month data during COVID-19 period from 2020 (considered as "current" data) and the corresponding data from 2017 to 2019 (considered "historical" data) are compared in Fig. 2. In Dongying, AQI reduced by 40.6, 16.2 and 25.4 during February 2020 compared with February 2017, 2018 and 2019, respectively. The differences in the AQI in Dongying between January and February in 2020 is about triple that of from 2018 and 2019. Variations of AQI depends on season to season, and months to months, depending upon the human activities, dust events and emissions from traffic. Due to short-term lockdown, most enterprises shut down, and human movement was restricted, AQI is declined in the month of February 2020. In addition, ANOVA was conducted to determine whether the AQI in February 2020 was statistically lower than that of the historical data. The statistical results revealed differences between 2020 and 2017, 2018, and 2019, with p values of $0.041,0.319$, and 0.008 , respectively, indicating significant differences (except for 2018) at the $5 \%$ level. Similar to "APEC blue" in China the decrease in the AQI indicates that reducing pollutant emissions is an effective means of improving air quality (Liu et al., 2015). Similar findings have been also reported for an urban area in Klang Valley, Malaysia (Mohd Nadzir et al., 2020; Suhaimi et al., 2020).

Since the effects of weather patterns (temperature, rain, wind speed, sunlight hours, or atmospheric pressure) can significantly affect pollutant concentrations and thereby compromise the observable effects of the lockdown (Venter et al., 2020), these meteorological factors in February were also taken into account to assess the short-term lockdown on AQI. The meteorological factor data were obtained by web crawling through the API provided by HEWeather (https://dev. hewe ather.com/). During February 2020, sunny weather occurred in $86.4 \%$ of days, the daily average temperature was approximately $-2.6^{\circ} \mathrm{C}$, and wind tended to be northerly with an average speed of $2.65 \mathrm{~m} \mathrm{~s}^{-1}$. Compared with the same periods during 2018-2019 (whose average temperature and wind speed were $1.5^{\circ} \mathrm{C}$ and $10.8 \mathrm{~km} \mathrm{~h}^{-1}$, respectively), the $\mathrm{p}$ values for ANOVA results for temperature and wind speed differences were 0.755 and 0.342 , respectively, suggesting that no obvious difference in temperature or wind existed, and the decrease in the AQI in February 2020 was likely related to strict lockdown measures. This result differs from that reported by 


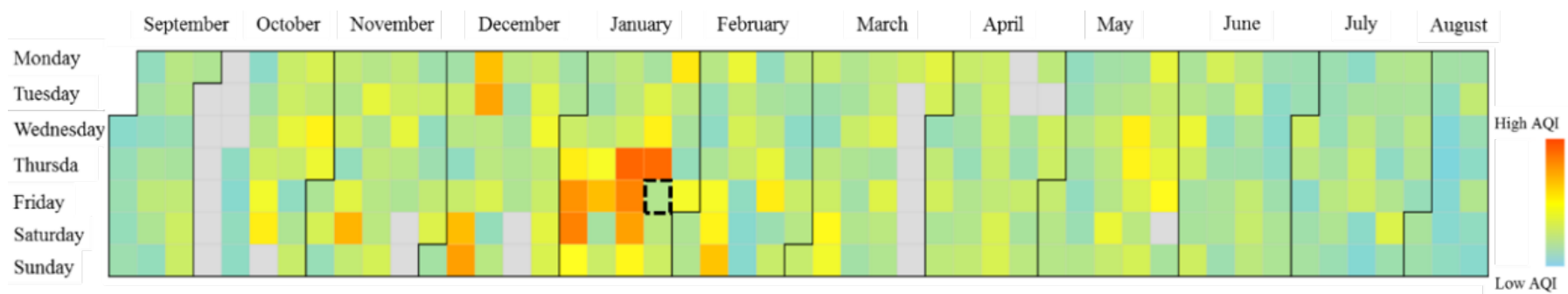

Fig. 3. Calendar heat. The gray color in (a) indicates no data.

Sun et al. (2020), where the effect of reduced local emissions on air quality improvement was significantly suppressed under stagnant meteorological conditions in Beijing.

Analyzing each AQI pollutant in February 2020, we uncovered that the main pollutants resulting in the improvement of air pollution in Dongying were $\mathrm{NO}_{2}, \mathrm{PM}_{2.5}, \mathrm{PM}_{10}, \mathrm{SO}_{2}$, and $\mathrm{CO}$, which are closely related to the emissions of petrochemical enterprises and automobiles. Compared with the concentrations in February 2019, concentrations of these pollutants in February 2020 were $49.9 \%, 26.5 \%, 34.0 \%, 41.8 \%$ and $23.3 \%$, lower, respectively, whereas the concentration of $\mathrm{O}_{3}$ increased by $4.5 \%$. Chen et al. (2020) revealed similar results; they identified a mild decreasing trend of concentrations of $\mathrm{PM}_{2.5}, \mathrm{PM}_{10}, \mathrm{SO}_{2}$, and $\mathrm{NO}_{2}$ in February in 2017-2019 but a sharp fall in $\mathrm{PM}_{2.5}, \mathrm{PM}_{10}, \mathrm{SO}_{2}, \mathrm{NO}_{2}$, and $\mathrm{CO}$ concentrations in February 2020 across China. The reason for the increase in the $\mathrm{O}_{3}$ concentration may be due to lower $\mathrm{NO}_{2}$ concentrations, hindering the $\mathrm{NO}+\mathrm{O}_{3}$ reaction, thus leading to an accumulation of $\mathrm{O}_{3}$.

Characteristics of the daily average AQI in Dongying are illustrated in Fig. 3. The color differences are more considerable for December and January. Several orange-red tiles were also observed for January, which corresponded to days before the Spring Festival, again a period of large-scale population movement with increased traffic intensity and air pollution. During the short-term lockdown period, color differences of daily AQI in February and March decreased significantly, and the percentage of polluted days decreased by $16 \%$.

\subsubsection{Hourly Characteristics}

Fig. 4 presents the analysis results of differences in the hourly AQI in the winter months and depicts hourly average AQI values in Dongying from December 2019 to February 2020. The highest AQI (i.e., 105) appeared at approximately 9 a.m., indicating a light pollution level (Wang et al., 2017; Li et al., 2018). However, Yao et al. (2015) reported a different finding, claiming that

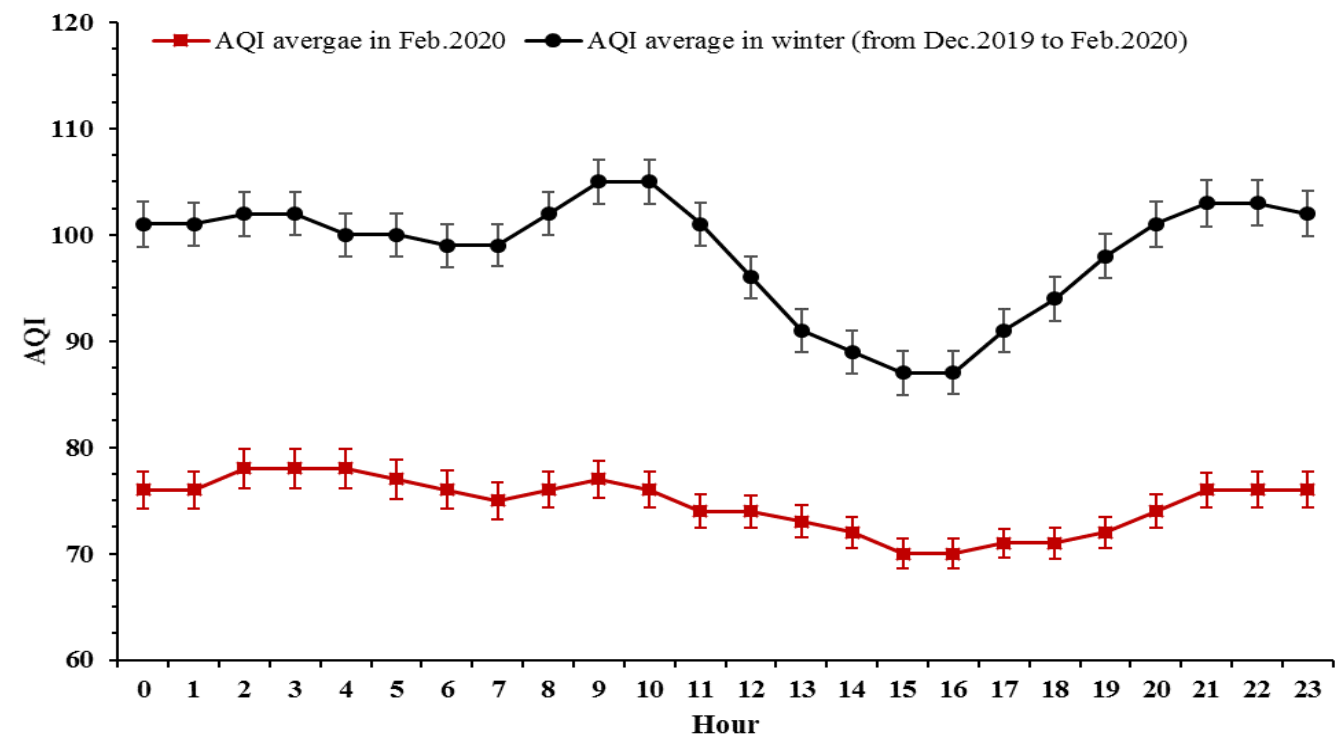

Fig. 4. Hourly average AQI values in Dongying (bars indicate standard error). 
air quality in Beijing was worst at 8 a.m. This may be due to that large urban areas such as Beijing may have greater distances between residence and workplace, residents living in cities like Beijing must leave for work earlier than those living in "fourth tier." This result corroborates the relevance of human activity to air quality.

By comparing the hourly average AQI value in Dongying, we discovered that the hourly average $A Q I$ in February (short-term lockdown period in Dongying), was relatively low. In addition, the difference between the peak and trough values was 8 , which was nearly one-third that of the study period. This result further illustrates that a series of measures including traffic restrictions, industry closure, and mass quarantine during the pandemic effectively reduced urban pollutant emissions and thus the negative effect of human activity on air quality. This finding concurs with that reported by Chen et al. (2020) for China as a whole. Although most factories were closed and traffic was restricted during the pandemic, air pollution remained a problem. Excessive pollutant emissions before the pandemic due to the normal operation of thermal power stations and winter heating, coupled with strong temperature inversion, caused persistent and irreversible effects on air quality. Nevertheless, the massive shutdown of pollution sources in February alleviated overall air pollution, to some extent.

\subsection{Spatial Distribution of the AQI in Dongying}

Fig. 5 represents the spatial distribution of the average monthly AQI in Dongying. Regardless of time, the AQI of Dongying was lower in the north and higher in the south. We infer that the general spatial distribution of AQI was not greatly affected by the COVID-19 pandemic. Among all regions, Guangrao County and Dongying District had more severe air pollution for two main reasons. First, these two areas host numerous industrial enterprises; second, these areas are densely populated. The topography and meteorology of Dongying also explain the north-lowsouth-high trend of pollutant concentration. The southern part of Dongying is an inland area adjacent to Zibo, a heavily industrialized city with severe air pollution. Substantial air pollutants and toxic particles from Zibo can spread westward, causing air pollution. With mostly northerly or northwesterly winds during winter, pollutants and dust particles from northwestern Dongying are transmitted to the southern area, thus worsening pollution there.

Notably, the AQI differences between northern and southern Dongying decreased during short-term lockdown period. In particular, during the non-pandemic period, such as November and December 2019, northeast Dongying generally displayed a low AQI. Located near the Bohai Sea, it has a smaller population and a lower level of industrial development and thus has higher air quality. In February, since most factories were required to close except for some iron and steel enterprises, coking enterprises, the difference in air quality between the southern area, where large-scale enterprises operate, and the northern area narrowed. The differences in the AQI between southern cities (Hekou, Lijin, and Kenli) and northern cities in December 2019, January 2020, and February 2020 were 24.5, 28.2, and 13.7, respectively. This indicates the effect of industrial emissions on air quality. Furthermore, in February, a ring-shaped area with a relatively high AQI appeared in the northeast of Hekou District, and difference in the AQI for these monitoring stations between January and February was only 7, which was lower than the average value of the city of Dongying (46). From a temporal angle, seasonally and monthly, pollution in Dongying showed wider distribution in winter. The AQI spatial gradient exhibited little change. During December and January 2020 in winter, the spatial gradient was the most apparent. As the weather became colder, pollution gradually spread northward. In January, pollution covered central, southern, and western Dongying. Although air quality in other areas changed remarkably during the months prior to the outbreak, it was consistently good in the coastal area of Hekou District. It is adjacent to the Bohai Sea, and coastal areas benefit from the influence of marineoriginated cleaning air masses, which are conducive for wet deposition and pollutant dilution.

\section{DISCUSSION AND POLICY IMPLICATIONS}

\subsection{Comparing the Existing Findings of Air Quality under COVID-19 Pandemic}

COVID-19 pandemic is a major problem facing humanity throughout the world. Many nations conducted the total lockdown within city or in whole country, which helped to break chain of 


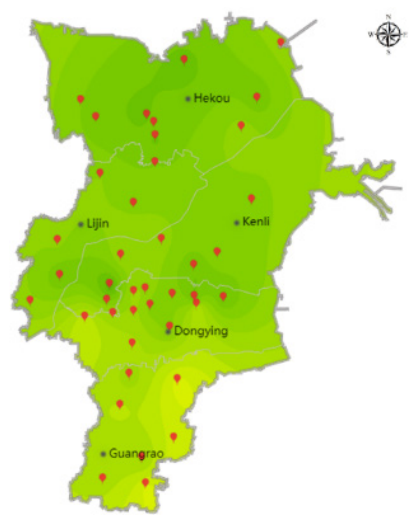

(a) September 2019

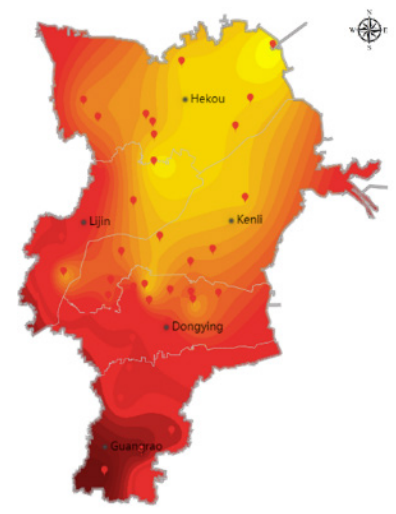

(e) January 2020

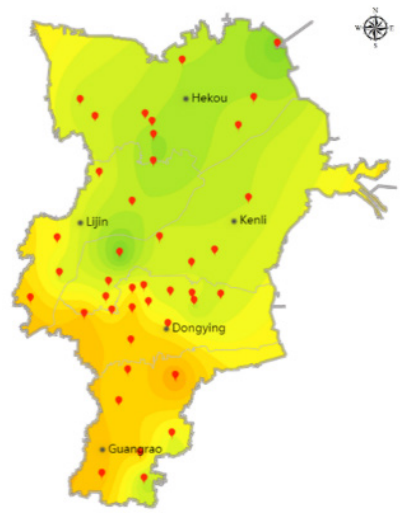

(i) May 2020

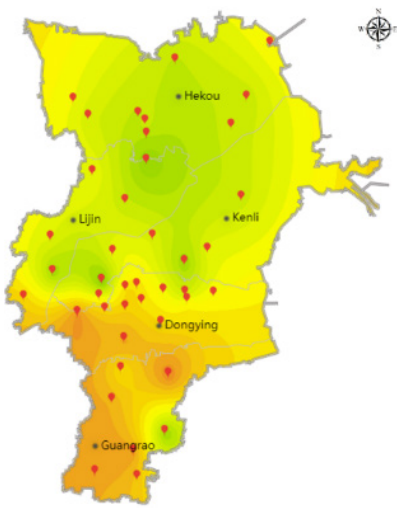

(b) October 2019

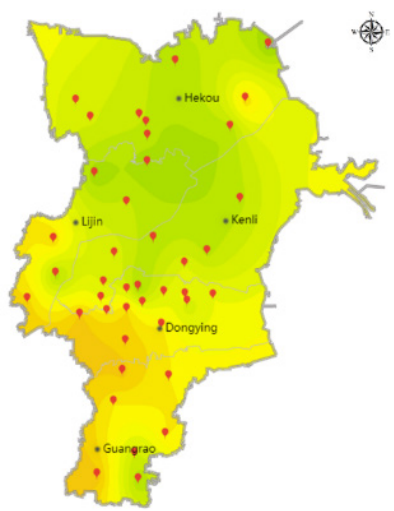

(f) February 2020

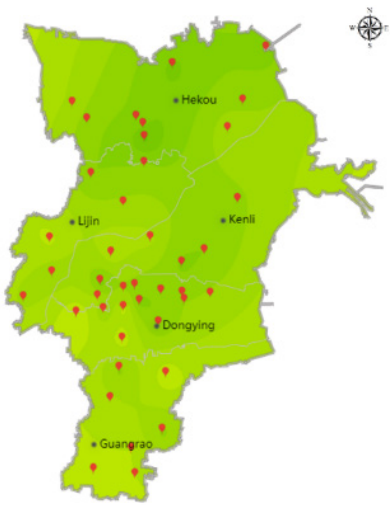

(j) June 2020

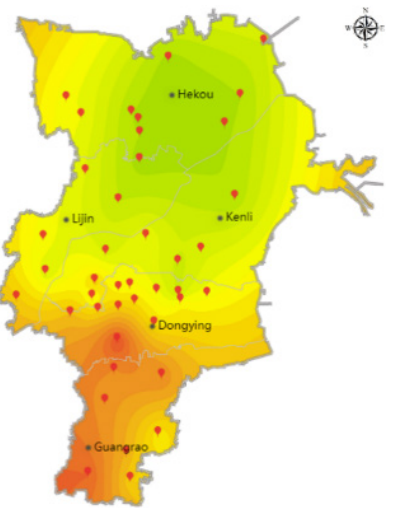

(c) November 2019

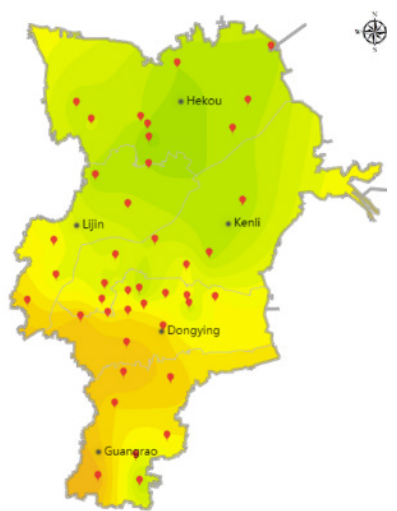

(g) March 2020

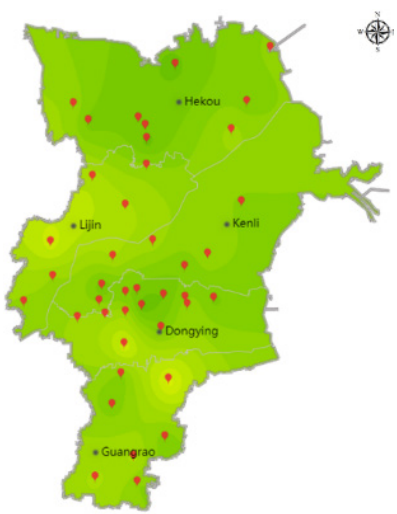

(k) July 2020

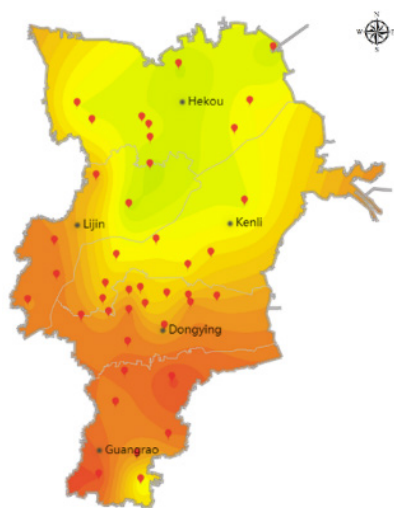

(d) December 2019

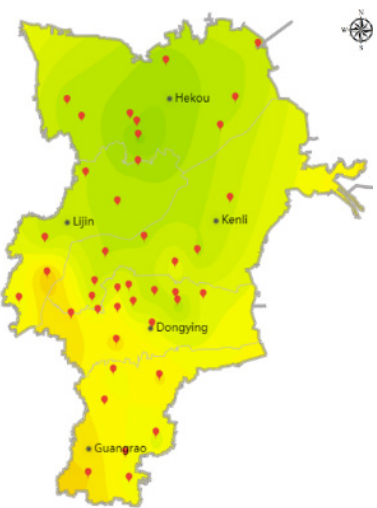

(h) April 2020

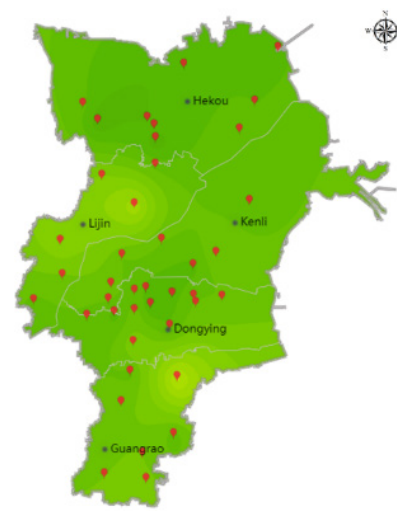

(I) August 2020
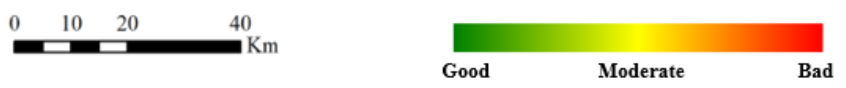

Fig. 5. Spatial distribution of monthly AQI in Dongying.

spread of virus. Simultaneously, such conditions helped in improving the air quality. Our findings present evidence that measured air quality has improved across China during the COVID-19 pandemic (February), which is similar to the study of Chauhan and Singh (2020) in major cities around the world and Wang et al. (2020) in cities of China. They showed that the decline in air pollution concentration during COVID-19 compared with other years is attributed to the lockdown, mainly due to less movement of people to keep social distancing to control the spread of COVID-19 (Berman and Ebisu, 2020). The low concentrations of air pollution reflect the efforts made in the cities to curb the spread of infection, thus improving air quality. In addition, for each air pollution component, our study shows a $49.5 \%$ reduction in $\mathrm{NO}_{2}$ compared with historical data in February. This reduction is larger than estimates from the U.S. and Spain (Muhammad et al., 2020). Satellite 
data from NASA found a similar 30\% reduction in $\mathrm{NO}_{2}$ during the month of March in the urban northeastern United States (Blumberg, 2020). Decreases in $\mathrm{NO}_{2}$ are likely related to reduced traffic and limited travel. Like the study in Spain during short-term lockdown period, which showed that the 4-week lockdown had significant impact on reducing the atmospheric levels of $\mathrm{NO}_{2}$ in all cities except for the small city of Santander as well as $\mathrm{CO}, \mathrm{SO}_{2}$, and $\mathrm{PM}_{10}$ in some cities (Briz-Redón et al., 2021).

\subsection{Quantitative Analysis for Meteorological Factors, Exhaust Emissions, and AQI}

A spatial regression model was employed to quantitatively analyze the different effects of meteorological factors and emissions on the AQI and to discuss relationships among daily exhaust emissions, temperatures, surface pressure, relative humidity, wind speed, and the AQI during the short-term lockdown period and other months from September 2019 to August 2020 in Dongying (Table 1). Information recorded at 232 exhaust emission monitoring sites (the locations are indicated in Fig. 1) was obtained from the Bureau of Ecological Environment of Dongying. A volatile organic compound (i.e., VOC) monitoring instrument for waste gas pollution sources was used to measure industrial exhaust emissions. The data collection frequency was 1 hour, and the unit for the monitoring data was $\mathrm{m}^{3} \mathrm{~h}^{-1}$. The daily emission values (unit: $\mathrm{m}^{3}$ ) were obtained by calculating the arithmetic mean value of the data collected at intervals of 1 hour every day.

The ordinary least-squares linear regression model explains AQI as a function of the five identified factors in different periods as follows:

$A Q I=a_{0}+a_{0} T+a_{1} S P+a_{2} R H+a_{4} W S+a_{5} E E$

where $\mathrm{T}$ is temperature, $\mathrm{SP}$ is surface pressure, $\mathrm{RH}$ is relative humidity, WS is wind speed, and EE is exhaust emissions.

Table 1 presents the $\mathrm{R}^{2}$ and standardized coefficients of the factors for different periods. The $A Q I$ had notable negative correlations with wind speed, with correlations statistically significant at $p<0.01$, and strong positive correlations with exhaust emissions in each period. These findings echo many previous studies which showed the negative correlation between the temperature and wind, and air pollution. However, the same finding is not observed in study of Zhan et al. (2018), which presented a positive relationship between AQI and wind speed, and reported that both downwind areas and dust-storm-prone areas are likely to suffer serious air pollution by increasing wind speed.

To determine whether the differences in the coefficients were significant, a statistical analysis ( $Z$ value) was conducted. The results indicate that, except for the differences in relative humidity, the wind speed and surface pressure in Period A (Sep 2019-Jan 2020) and short-term lockdown period, and wind speed in short-term lockdown period and Period C (Mar 2020-Aug 2020), all the differences in the coefficients for the periods were significant at the $5 \%$ level. The Z-score of the differences in exhaust emission coefficients for Period A and lockdown period is 3.134, and the Z-score between the lockdown period and Period C is 2.366 .

The coefficients of these factors fluctuated and differed. For instance, temperature had a significant negative relationship with AQI during the short-term lockdown period, but the relationship was nonsignificant in other periods. Relative humidity and wind speed had the strongest negative relationships with AQI in Period C. As presented in Table 1, during the shortterm lockdown period, the standardized coefficients between exhaust emission and AQI were

Table 1. Standardized coefficients of meteorological factors and exhaust emissions at different periods.

\begin{tabular}{|c|c|c|c|c|c|c|}
\hline \multirow{2}{*}{ Periods } & \multicolumn{5}{|c|}{ Standardized coefficients } & \multirow{2}{*}{$\mathrm{R}^{2}$} \\
\hline & $\mathrm{EE}$ & $T$ & SP & $\mathrm{RH}$ & WS & \\
\hline Period A (Sep 2019-Jan 2020) & $0.501^{* *}$ & -0.171 & $0.535^{* *}$ & $0.185^{* *}$ & $-0.015^{* *}$ & 0.574 \\
\hline Short-term lockdown period (Feb 2020) & $0.296^{* *}$ & $-0.549^{*}$ & $0.222^{*}$ & $-0.233^{*}$ & $-0.185^{* *}$ & 0.506 \\
\hline Period C (Mar 2020-Aug 2020) & $0.451^{* *}$ & -0.149 & 0.032 & $-0.336^{* *}$ & $-0.109^{*}$ & 0.476 \\
\hline
\end{tabular}

Note: ${ }^{*} p<0.05,{ }^{* *} p<0.01$. 
the smallest, indicating that during the pandemic the effect of exhaust emissions on AQI in Dongying were significantly reduced; this may be related to the lockdown measures in China during the period. Compared with Period A emissions, the average monthly exhaust emissions during the pandemic decreased by $34.4 \%$.

\subsection{Policy Recommendations}

Comprehensive analysis of spatiotemporal characteristics of AQI in Dongying revealed that although the city had good to excellent air quality on most days, days with severe air pollution occurred. Overall, air quality in Dongying was far from excellent (AQI < 50). In addition, relying on the Statistics Yearbook of Statistical Bulletin of National Economic and Social Development of Dongying in 2019 and analyzing the emissions of different industries, we determined that the main industry of Dongying is petroleum exploitation and processing. In the process of petroleum exploitation, with the combustion of fuel fossils, a large amount of nitrogen-containing waste gas is produced, resulting in $\mathrm{NO}_{x}$ pollution. Although $\mathrm{VOC}_{x}$ can also be produced, as a whole, Dongying is dominated by a $\mathrm{NO}_{x}$-limited environment. Therefore, under consideration of this limited environment and the findings of this study, the following policy recommendations to prevent and control air pollution in Dongying are presented.

Pollution prevention should be enforced during non-pandemic winters, and evergreen trees should be planted. Considering the characteristics of Dongying, it is recommended that Dongying should strengthen the planting of evergreen trees, for instance, Pinus bungeana Zucc., Pinus tabuliformis Carr., Euonymus japonicus Thunb. and Lolium perenne L. (Pal et al., 2002; Li et al., 2020). Dongying had the highest AQI values in winter under normal conditions (i.e., without a pandemic). Thus, seasonal differences in air pollution should be fully considered, and measures such as increasing the use of cold season lawns and evergreen trees to effectively reduce and control pollutants in winter should be enforced.

Low-carbon living and green travel should be promoted. Comparing AQI in lockdown period and historical data, we observed that quarantine and large-scale traffic restrictions significantly reduced air pollution, indicating that the air quality of Dongying is closely related to human activity. Under future non-pandemic conditions, governments could encourage residents to adopt green travel by optimizing bus routes and increasing the number of shared bicycles, thereby alleviating $\mathrm{NO}_{x}$ emissions and air pollution.

Industrial transformation and supervision should be reinforced. The economic development of Dongying is supported mainly by petroleum and chemical engineering enterprises, which bring both economic benefits and air pollution. During the lockdown period, the shuttering of factories significantly reduced regional pollution. Governments can learn from the experience of lockdown measures taken during the pandemic to control pollution sources. For example, enforcing the purification of industrial waste gas is recommended to eliminate pollution sources. Enforcing industrial supervision therefore is a necessity. Governments can monitor and frequently and irregularly conduct spot checks on enterprises with severe pollution to reduce industrial emissions on weekends.

According to hourly AQI characteristics from September 2019 to August 2020, air quality at 3 p.m. or 4 p.m. in Dongying was the best. Hence, we recommend that residents participate in outdoor sports as much as possible during this period to reduce the risk of respiratory or cardiovascular diseases caused by air pollution. Although this paper does not provide hourly characteristics of Dongying in summer, according to a previous study of a similar city (Weifang), the best air quality usually occurs at 5 p.m. (Li et al., 2019). The finding of this paper supports Chen et al. (2020), who recommended that residents in China go out in the afternoon.

\section{CONCLUSIONS}

Using Dongying, a city known for petroleum exploration, as a case study, we investigated the spatiotemporal characteristics of the AQI from September 2019 through August 2020 and evaluated the effect of the February 2020 lockdown. Our main conclusions are as follows.

During February 2020, the AQI fell by 16.2 and 25.4 compared to the same months in 2018 and 2019, respectively. Reductions in $\mathrm{NO}_{2}, \mathrm{PM}_{2.5}, \mathrm{PM}_{10}, \mathrm{SO}_{2}$, and $\mathrm{CO}$, which are closely related to 
industrial and vehicular emissions, were primarily responsible for the improvement in air quality. Moreover, the difference between the maximum and the minimum hourly average AQI decreased to one-third of the value that in the normal period.

The lockdown minimally affected the usual AQI spatial distribution in Dongying, i.e., high and low values in the south and the north, respectively. However, the difference in AQI between these two areas diminished during this period, demonstrating the positive effect of enterprise closures on the air quality.

The standardized coefficients for the correlation between the AQI and industrial exhaust emissions in Dongying dropped to their minimum values during February 2020, showing a significantly lessened contribution from the latter to the former. Hence, the decrease in AQI was closely related to the reduction in industrial exhaust emissions. Additionally, the AQI displayed negative correlations with the air temperature and the wind speed.

Exhaust emissions and human activity critically affect the air quality, especially in a city dominated by the petrochemical industry, but the impracticality of stopping the largest sources of pollution, viz., enterprises and vehicles, prevented previous studies from accurately quantifying their contributions. The COVID-19 outbreak provided a real-world opportunity to assess the effects of emission reduction. The methods we applied, including quantitative analysis, can be used to characterize other relationships, and our results serve as a reference for mitigating air pollution in Dongying and similar areas.

However, this work is subject to certain limitations. For instance, we mainly based our air quality measurements on ground-based monitoring data, which do not capture vertical information on pollutants. Hence, we will combine ground-based and remotely sensed monitoring data in a future study in order to control extrapolation errors/bias and integrate the vertical information. Other interpolation techniques that address both spatial and temporal characteristics may also be considered. Furthermore, although the current study quantitatively analyzed the influence of the air temperature and other factors on the AQI, subsequent research should incorporate more complex data, such as the type of land use or human activity, in addition to integrating statistical analyses. Lastly, our spatiotemporal analysis of the air quality potentially ignores the roles of photochemical reactions, etc., which will be addressed in future work.

\section{REFERENCES}

Alsahli, M.M., Al-Harbib, M. (2018). Allocating optimum sites for air quality monitoring stations using GIS suitability analysis. Urban Clim. 24, 875-886. https://doi.org/10.1016/j.uclim.2017.1 1.001

Bauwens, M., Compernolle, S., Stavrakou, T., Müller, J.F., Gent, J. van, Eskes, H., Levelt, P.F., A, R. van der, Veefkind, J.P., Vlietinck, J., Yu, H., Zehner, C. (2020). Impact of coronavirus outbreak on $\mathrm{NO}_{2}$ pollution assessed using TROPOMI and OMI observations. Geophys. Res. Lett. 47, e2020GL087978. https://doi.org/10.1029/2020GL087978

Berman, J., Ebisu, K. (2020). Changes in U.S. air pollution during the COVID-19 pandemic. Sci. Total Environ.,739, 139864. https://doi.org/10.1016/j.scitotenv.2020.139864

Blumberg, S. (2020). Data shows 30 percent drop in air pollution over northeast U.S. NASA. http://www.nasa.gov/feature/goddard/2020/dropin-air-pollution-over-northeast (accessed 5 February 2020).

Briz-Redón, A., Belenguer-Sapiña, C., Serrano-Aroca, Á. (2021). Changes in air pollution during COVID-19 lockdown in Spain: A multi-city study. J. Environ. Sci. 101, 16-26. https://doi.org/10. 1016/j.jes.2020.07.029

Chambers, J., Hastie, T., Pregibon, D. (1992). Statistical Models in S. Wadsworth \& Brooks/Cole.

Chauhan, A., Singh, R. (2020). Decline in $\mathrm{PM}_{2.5}$ concentrations over major cities around the world associated with COVID-19. Environ. Res. 187, 109634. https://doi.org/10.1016/j.envres.2020.1 09634

Chen, H., Huo, J., Fu, Q., Duan, Y., Xiao, H., Chen, J. (2020). Impact of quarantine measures on chemical compositions of $\mathrm{PM}_{2.5}$ during the COVID-19 epidemic in Shanghai, China. Sci. Total Environ. 743, 140758. https://doi.org/10.1016/j.scitotenv.2020.140758 
Chen, T., He, J., Lu, X., She, J., Guan, Z. (2016). Spatial and temporal variations of $\mathrm{PM}_{2.5}$ and its relation to meteorological factors in the urban area of Nanjing, China. Int. J. Environ. Res. Public Health 13, 921. https://doi.org/10.3390/ijerph13090921

Chudnovsky, A.A., Koutrakis, P., Kloog, I., Melly, S., Nordio, F., Lyapustin, A., Wang, Y., Schwartz, J. (2014). Fine particulate matter predictions using high resolution Aerosol Optical Depth (AOD) retrievals. Atmos. Environ. 89, 189-198. https://doi.org/10.1016/j.atmosenv.2014.02.019

Dutheil, F., Baker, J.S., Navel, V. (2020). COVID-19 as a factor influencing air pollution? Environ. Pollut. 263, 114466. https://doi.org/10.1016/j.envpol.2020.114466

Glencross, D.A., Ho, T.R., Camiña, N., Hawrylowicz, C.M., Pfeffer, P.E. (2020). Air pollution and its effects on the immune system. Free Radic. Biol. Med. 151, 56-68. https://doi.org/10.1016/j.fre eradbiomed.2020.01.179

Guo, Y.R., Cao, Q.D., Hong, Z.S., Tan, Y.Y., Chen, S.D., Jin, H.J., Tan, K.S., Wang, D.Y., Yan, Y. (2020). The origin, transmission and clinical therapies on coronavirus disease 2019 (COVID-19) outbreak - an update on the status. Mil. Med. Res. 7, 11. https://doi.org/10.1186/s40779-020-00240-0

Gupta, S., Raghuwanshi, G.S., Chanda, A. (2020). Effect of weather on COVID-19 spread in the US: A prediction model for India in 2020. Sci. Total Environ. 728, 138860. https://doi.org/10.1016/ j.scitotenv.2020.138860

Huang, Y., Yan, Q., Zhang, C. (2018). Spatial-temporal distribution characteristics of $\mathrm{PM}_{2.5}$ in China in 2016. J. Geovis. Spat. Anal. 2, 12. https://doi.org/10.1007/s41651-018-0019-5

Khaparde, V.V., Pipalatkar, P.P., Pustode, T., Rao, C.V.C., Gajghate, D.G. (2012). Influence of burning of fireworks on particle size distribution of $\mathrm{PM}_{10}$ and associated Barium at Nagpur. Environ. Monit. Assess. 184, 903-911. https://doi.org/10.1007/s10661-011-2008-8

Li, C., Dai, Z., Yang, L., Ma, Z. (2019). Spatiotemporal characteristics of air quality across Weifang from 2014-2018. Int. J. Environ. Res. Public Health 16, 3122. https://doi.org/10.3390/ijerph16 173122

Li, C., Zhang, K., Dai, Z., Ma, Z., Liu, X. (2020). Investigation of the impact of land-use distribution on $\mathrm{PM}_{2.5}$ in Weifang: Seasonal variations. Int. J. Environ. Res. Public Health 17, 5135. https://doi.org/10.3390/ijerph17145135

Li, Y.X., Dai, Z.X., Liu, X.L. (2018). Analysis of spatial-temporal characteristics of the $\mathrm{PM}_{2.5}$ concentrations in Weifang city, China. Sustainability 10, 2906. https://doi.org/10.3390/su1009 2960

Liu, J., Zhou, J., Yao, J., Zhang, X., Li, L., Xu, X., He, X., Wang, B., Fu, S., Niu, T., Yan, J., Shi, Y., Ren, X., Niu, J., Zhu, W., Li, S., Luo, B., Zhang, K. (2020). Impact of meteorological factors on the COVID-19 transmission: A multi-city study in China. Sci. Total Environ. 726, 138513. https://doi.org/10.1016/j.scitotenv.2020.138513

Liu, Y.S., Li, Y., Chen, C. (2015). Pollution: Build on success in China. Nature 517, 145-145. https://doi.org/10.1038/517145d

Ma, Y., Zhao, Y., Liu, J., He, X., Wang, B., Fu, S., Yan, J., Niu, J., Zhou, J., Luo, B. (2020). Effects of temperature variation and humidity on the death of COVID-19 in Wuhan, China. Sci. Total Environ.724, 138226. https://doi.org/10.1016/j.scitotenv.2020.138226

Mahajan, S., Tang, Y.S., Wu, D.Y., Tsai, T.C., Chen, L.J. (2019). CAR: The clean air routing algorithm for path navigation with minimal PM2.5 exposure on the move. IEEE Access 7, 147373-147382. https://doi.org/10.1109/ACCESS.2019.2946419

Mannucci, P., Franchini, M. (2017). Health effects of ambient air pollution in developing countries. Int. J. Environ. Res. Public Health. 14, 1048. https://doi.org/10.3390/ijerph14091048

Masiol, M., Zíková, N., Chalupa, D.C., Rich, D.Q., Ferro, A.R., Hopke, P.K. (2018). Hourly land-use regression models based on low-cost PM monitor data. Environ. Res. 167, 7-14. https://doi.org/10.1016/j.envres.2018.06.052

Mohd Nadzir, M.S., Ooi, M.C.G., Alhasa, K.M., Bakar, M.A.A., Mohtar, A.A.A., Nor, M.F.F.M., Latif, M.T., Hamid, H.H.A., Ali, S.H.M., Ariff, N.M., Anuar, J., Ahamad, F., Azhari, A., Hanif, N.M., Subhi, M.A., Othman, M., Nor, M.Z.M. (2020). The impact of movement control order (MCO) during pandemic COVID-19 on local air quality in an urban area of Klang Valley, Malaysia. Aerosol Air Qual. Res. 20, 1237-1248. https://doi.org/10.4209/aaqr.2020.04.0163

Muhammad, S., Long, X., Salman, M., (2020). COVID-19 pandemic and environmental pollution: A blessing in disguise? Sci. Total Environ. 728, 138820. https://doi.org/10.1016/j.scitotenv.202 0.138820 
Pal, A., Kulshreshtha, K., Ahmad, K.J., Behl, H.M. (2002). Do leaf surface characters play a role in plant resistance to auto-exhaust pollution? Flora 197, 47-55. https://doi.org/10.1078/03672530-00014

Pani, S.K., Lin, N.H. (2020). Association of COVID-19 pandemic with meteorological parameters over Singapore. Sci. Total Environ. 740, 140112. https://doi.org/10.1016/j.scitotenv.2020.140 112

Pastuszka, J.S., Rogula-Kozłowska, W., Zajusz-Zubek, E. (2010). Characterization of PM10 and $\mathrm{PM}_{2.5}$ and associated heavy metals at the crossroads and urban background site in Zabrze, Upper Silesia, Poland, during the smog episodes. Environ. Monit. Assess. 168, 613-627. https://doi.org/10.1007/s10661-009-1138-8

Suhaimi, N.F., Jalaludin, J., Latif, M.T. (2020). Demystifying a possible relationship between COVID-19, air quality and meteorological factors: Evidence from Kuala Lumpur, Malaysia. Aerosol Air Qual. Res. 20, 1520-1529. https://doi.org/10.4209/aaqr.2020.05.0218

Sun, Y., Lei, L., Zhou, W., Chen, C., He, Y., Sun, J., Li, Z., Xu, W., Wang, Q., Ji, D., Fu, P., Wang, Z., Worsnop, D.R. (2020). A chemical cocktail during the COVID-19 outbreak in Beijing, China: Insights from six-year aerosol particle composition measurements during the Chinese New Year holiday. Sci. Total Environ. 742, 140739. https://doi.org/10.1016/j.scitotenv.2020.140739

Venter, Z.S., Aunan, K., Chowdhury, S., Lelieveld, J. (2020). COVID-19 lockdowns cause global air pollution declines. PNAS 117, 18984-18990. https://doi.org/10.1073/pnas.2006853117

Wang, F., Peng, Y.Y., Jiang, C.Y. (2017). Influence of road patterns on $\mathrm{PM}_{2.5}$ concentrations and the available solutions: The case of Beijing city, China. Sustainability 9, 217. https://doi.org/10. 3390/su9020217

Wang, P., Chen, K., Zhu, S., Wang, Peng, Zhang, H. (2020). Severe air pollution events not avoided by reduced anthropogenic activities during COVID-19 outbreak. Resour. Conserv. Recycl. 158, 104814. https://doi.org/10.1016/j.resconrec.2020.104814

Wang, T., Shi, M.Q., Chen, X.J., Xu, S.W., Cao, Y., Ji, M., Liu, Z.Y., Kang, H.Y. Xia, Z.H. (2015). Characteristics of $\mathrm{PM}_{2.5}$ pollution in Beijing during Chunyun. Environ. Chem. 34, 2127-2129. (in Chinese)

Wang, Z., Tian, Z. (2018). Temporal and spatial distribution characteristics and influencing factors of air quality index in Xuchang. IOP Conf. Ser.: Earth Environ. Sci 108, 042107. https://doi.org/ 10.1088/1755-1315/108/4/042107

Wu, C., Zeng, Y., Lung, S. (2018). A hybrid kriging/land-use regression model to assess $\mathrm{PM}_{2.5}$ spatial-temporal variability. Sci. Total Environ. 15, 1456-1464. https://doi.org/10.1016/j.scitot env.2018.07.073

Xu, K., Cui, K., Young, L.H., Hsieh, Y.K., Wang, Y.F., Zhang, J., Wan, S. (2020). Impact of the COVID-19 event on air quality in central China. Aerosol Air Qual. Res. 20, 915-929. https://doi.org/10.42 09/aaqr.2020.04.0150

Yao, L., Lu, N., Yue, X., Du, J., Yang, C. (2015). Comparison of hourly PM2.5 observations BETWEEN urban and suburban areas in Beijing, China. Int. J. Environ. Res. Public Health 12, 12264-12276. https://doi.org/10.3390/ijerph121012264

Zhan, D., Kwan, M.P., Zhang, W., Yu, X., Meng, B., Liu, Q. (2018). The driving factors of air quality index in China. J. Cleaner Prod. 197, 1342-1351. https://doi.org/10.1016/j.jclepro.2018.06.108

Zhao, D., Chen, H., Li, X., Ma, X. (2018). Air pollution and its influential factors in China's hot spots. J. Cleaner Prod. 185, 619-627. https://doi.org/10.1016/j.jclepro.2018.02.181

Zhou, X., Cao, Z., Ma, Y., Wang, L., Wu, R., Wang, W. (2016). Concentrations, correlations and chemical species of $\mathrm{PM}_{2.5} / \mathrm{PM}_{10}$ based on published data in China: Potential implications for the revised particulate standard. Chemosphere 144, 518-526. https://doi.org/10.1016/j.chem osphere.2015.09.003 